presented at the

1995 Spring Meeting of the Materials Research Society

San Francisco, April 17-21, 1995

Symposium Q: Film Synthesis and Growth Using Energetic Ion Beams

(Paper Q 9.3)

\title{
FILM SYNTHESIS ON POWDERS BY CATHODIC ARC PLASMA DEPOSITION
}

\author{
ANDRÉ ANDERS*, SIMONE ANDERS*, IAN G. BROWN*, \\ AND IGOR C. IVANOV**
}

*Lawrence Berkeley Laboratory, University of California, Berkeley, CA 94720

**Charles Evans \& Associates, Redwood City, CA 94063

This work was supported by the Electric Power Research Institute under RP 8042-03 and the U.S. Department of Energy, Division of Advanced Energy Projects, under contract No. DEAC03-76SF00098. 


\section{DISCLAIMER}

This report was prepared as an account of work sponsored by an agency of the United States Government. Neither the United States Government nor any agency thereof, nor any of their employees, make any warranty, express or implied, or assumes any legal liability or responsibility for the accuracy, completeness, or usefulness of any information, apparatus, product, or process disclosed, or represents that its use would not infringe privately owned rights. Reference herein to any specific commercial product, process, or service by trade name, trademark, manufacturer, or otherwise does not necessarily constitute or imply its endorsement, recommendation, or favoring by the United States Government or any agency thereof. The views and opinions of authors expressed herein do not necessarily state or reflect those of the United States Government or any agency thereof. 


\section{DISCLAIMER}

Portions of this document may be illegible in electronic image products. Images are produced from the best available original document. 


\title{
FILM SYNTHESIS ON POWDERS BY CATHODIC ARC PLASMA DEPOSITION
}

\author{
ANDRÉ ANDERS*, SIMONE ANDERS*, IAN G. BROWN*, \\ AND IGOR C. IVANOV** \\ * Lawrence Berkeley Laboratory, University of California, Berkeley, CA 94720 \\ ** Charles Evans \& Associates, 301 Chesapeake Drive, Redwood City, CA 94063
}

\begin{abstract}
Cathodic arc plasma deposition was used to coat $\mathrm{Al}_{2} \mathrm{O}_{3}$ powder (mesh size 60 ) with platinum. The power particles were moved during deposition using a mechanical system operating at a resonance frequency of $20 \mathrm{~Hz}$. Scanning electron microscopy and Auger electron microscopy show that all particles are completely coated with a platinum film having a thickness of about $100 \mathrm{~nm}$. The actual deposition time was only $20 \mathrm{~s}$, thus the deposition rate was very high $(5 \mathrm{~nm} / \mathrm{s})$.
\end{abstract}

\section{INTRODUCTION}

Coating of powders is of interest for a number applications such as catalysis and powder metallurgy and ceramic powder sintering. In particular, coating of ceramic powder with platinum is of interest in catalysis due to the large platinum surface area per mass unit. Complete coverage of the particles is sometimes difficult to achieve, and adhesion of the film to powder grains can be a problem.

Powder coatings are generally done by fluidized-bed chemical vapor deposition [1], rotarybed chemical vapor deposition [2], rotary-bed physical vapor deposition [3] or in-situ precipitation in aqueous solvents [4] or non-aqueous solvents [5].

In the present paper we describe a new approach to film synthesis on power particles using cathodic arc plasma deposition. In section II we outline the features and capabilities of cathodic arc plasma deposition in general, and focus in section III on the application of coatings on power particles. As an example we deposited platinum on alumina powder.

\section{CATHODIC ARC PLASMA DEPOSITION}

A high current discharge between a cold cathode and an anode in vacuum or in a gas is called a "cathodic arc". The term "vacuum arc" is frequently used if no gas is present. Cathodic arcs are characterized by plasma production at small, non-stationary cathode spots (see, for instance, [6-8]). The arc current of typically $100 \mathrm{~A}$ or more is concentrated in a few micron-sized spots which move quickly over the cathode surface. The number of simultaneously active cathode spots depends on current, cathode material and temperature, and cathode surface conditions. Since the current density can be as high as $10^{12} \mathrm{~A} / \mathrm{m}^{2}$ [9], the solid cathode material is transformed into a completely ionized plasma which leaves the cathode spot region with a velocity of $1-2 \times 10^{4} \mathrm{~m} / \mathrm{s}$ (this number is valid for all cathode materials). This velocity corresponds to kinetic ion energies in the range from $20 \mathrm{eV}$ (light ions such as carbon) to $300 \mathrm{eV}$ (heavy ions such as platinum). Thus the cathode material is eroded and forms an energetic plasma jet. A current-carrying part of the plasma streams to the anode, and another part of the plasma can be used to synthesize metal films on arbitrary substrates. Sometimes the term "cathodic arc evaporation" is used. This is term suggests misleadingly that neutral vapor is involved. However, it is fully ionized plasma that is actually used in depositing a film.

Cathodic arc plasma deposition can operate in the complete absence of any gases ("vacuum arc plasma deposition"), and thus pure metal films are be obtained. If the cathodic arc is operated 
in reactive gases (e.g., nitrogen, oxygen), compound films can be formed (e.g., nitrides, oxides). Due to the high ion energy, the films formed have very interesting properties such as high density, smooth surface, and good adhesion. It is believed that a broad intermixed region which forms between the substrate and the film is responsible for the observed good adhesion properties. Cathodic arc plasma deposition of TiN films $[10,11]$ and (hydrogen-free) hard amorphous carbon films $[12,13]$ have been up to now the most successful applications of the method.

Cathodic arc plasma deposition can be modified by filtering the plasma prior deposition to remove micron-size "macroparticles" and a small neutral component $[14,15]$. Some applications such as optical coatings require filtering to obtain acceptable film quality. Other applications such as metallurgical coatings can be done without filtering but with very high deposition rate [16]. Another modification of cathodic arc plasma deposition results when a negative bias is applied to the (conductive) substrate. An electric sheath forms around the substrate, and ions are accelerated in the sheath and arrive at the surface with an energy given by the sheath voltage and ion charge state. This represents an alternative way of doing ion implantation [17]. Because we used (nonconductive!) alumina powders in the present experiments, no substrate bias was applied.

\section{EXPERIMENT}

The metal plasma in our experiments was produced using a small cathodic arc plasma gun (Fig. 1). The cathode is a rod made of the material to be transformed into a plasma (here platinum). The cathode rod is insulated from an annular anode cylinder by an alumina ceramic tube. Each arc pulse is triggered by a surface flashover from a trigger electrode to the cathode surface (trigger duration about $10 \mu \mathrm{s}$, trigger current $4 \mathrm{~A}$, initial voltage $12 \mathrm{kV}$ ). The voltage between cathode and anode breaks down to about $20 \mathrm{~V}$ after the arc is triggered. Cathode spots burn only on the front face of the cathode rod because the rest of the cathode is shielded by the ceramic tube. More details and photos of our cathodic arc sources have been published previously [17].

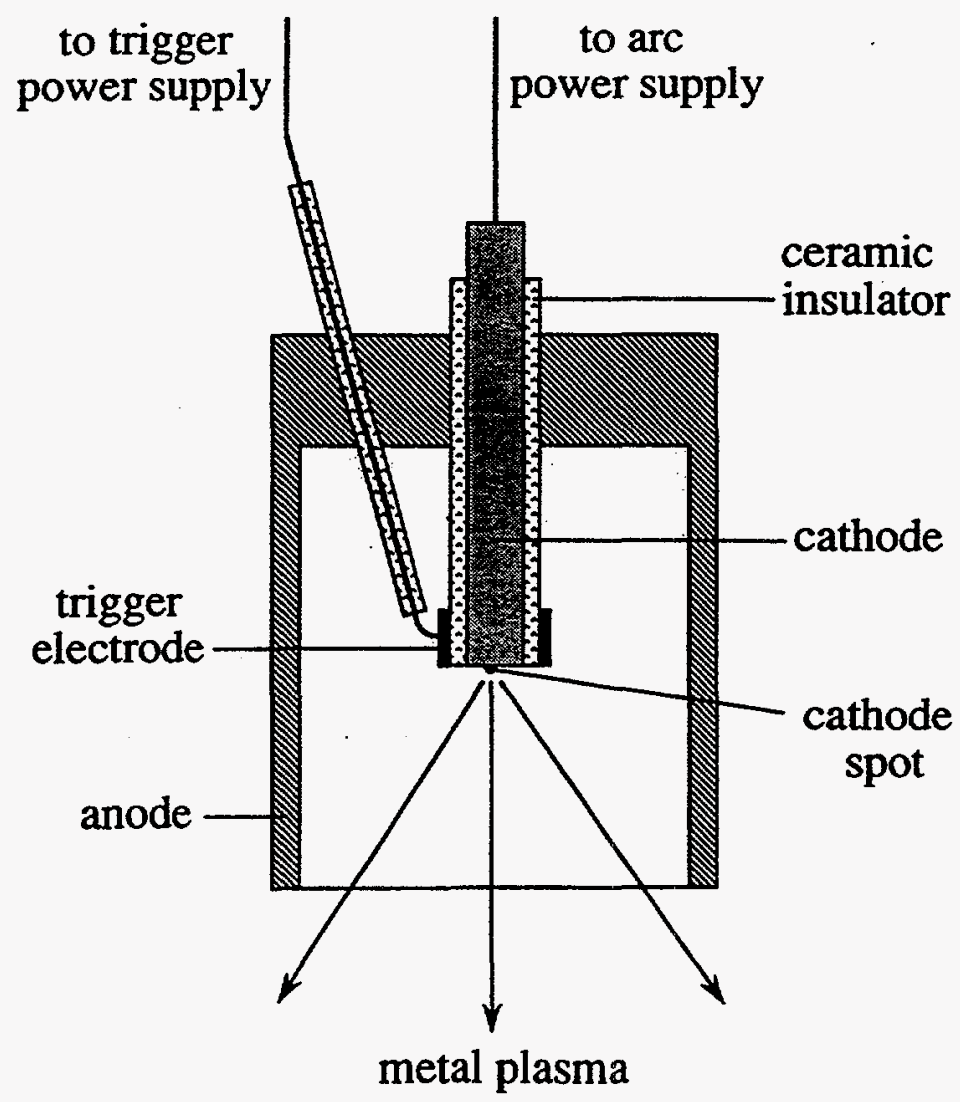

Fig. 1 Construction of cathodic arc plasma source 
Cathodic arc plasma deposition has been used up to now for deposition of metal or compound films on more-or-less regularly formed, relatively large substrates. There is no report to our knowledge - about coatings on powder particles. Since the flow of plasma from a cathodic arc plasma source is directional, not all sides of a substrate or sample are coated but only the side facing the source. In order to obtain a film covering all sides, either the substrate or the source must be moved, and we have done this in the past (substrate movement [18], source movement [19]). A powder, however, consists of many "individual miniature substrates" so that this conventional approach will not work.

The usual approach is to move many powder particles simultaneously in a rotary bed (see, for instance, [2-5]). Another approach is to use a mechanical resonance system. We modified a large loudspeaker system to make it vacuum compatible and mounted it on a frame (Fig. 2). A Petri dish of $5 \mathrm{~cm}$ diameter was attached to the moving central magnet. Powder was put in the Petri dish and remained there during evacuation held by gravity. The pressure was $3 \times 10^{-7}$ Torr $\left(4 \times 10^{-5} \mathrm{~Pa}\right)$. For most experiments we used $\mathrm{Al}_{2} \mathrm{O}_{3}$ powder (activated, neutral, gamma, $96 \%$ purity of metal basis, from Johnson Matthey Electronics) of mesh size 60, corresponding to grain sizes of $250 \mu \mathrm{m}$ and smaller.

Above this mechanical arrangement we mounted a vacuum arc plasma source which was equipped with a platinum cathode (rod diameter $6.2 \mathrm{~mm}$ ). Platinum was chosen due to its importance in catalysis. The distance between source exit and Petri dish was $5 \mathrm{~cm}$.

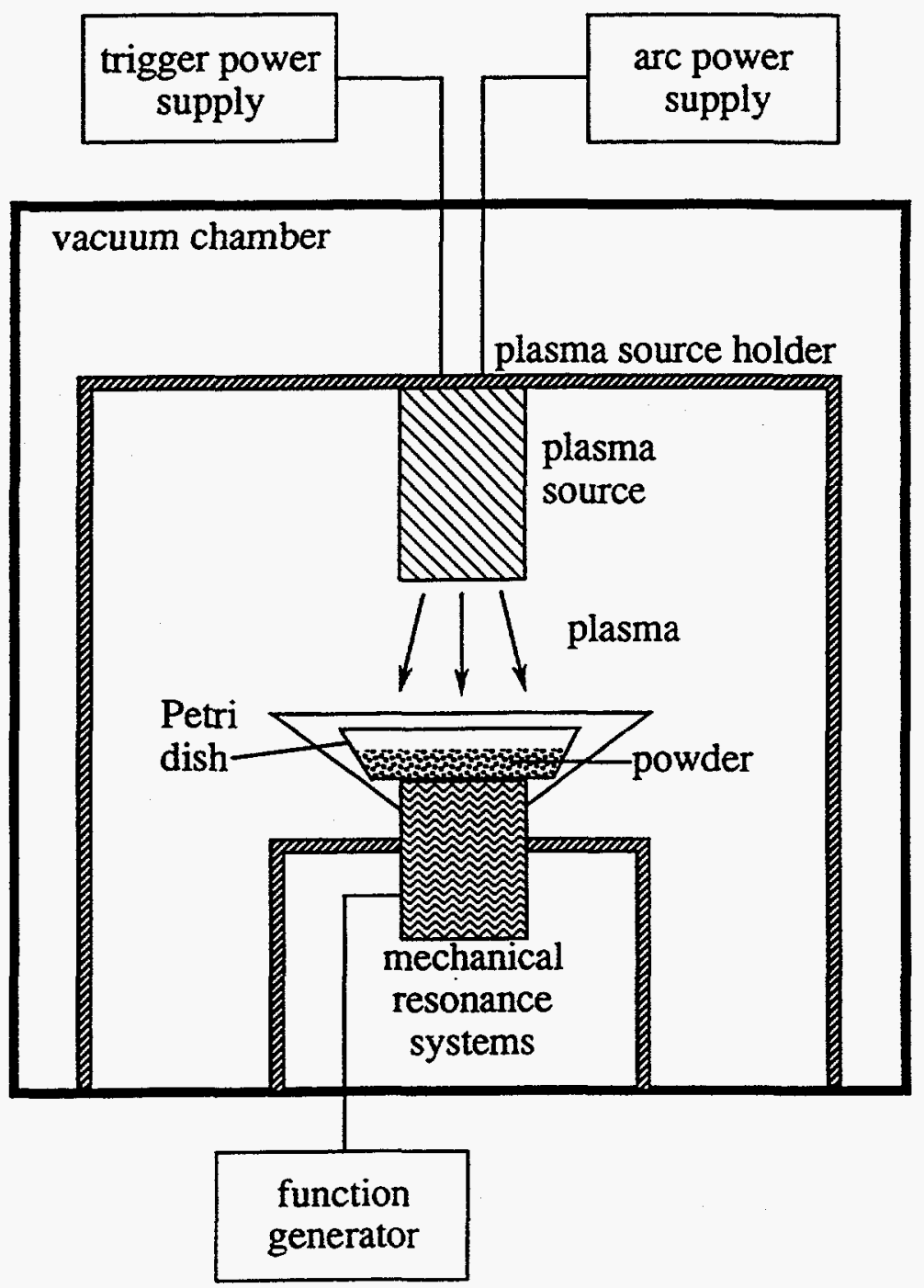

Fig. 2 Experimental arrangement for cathodic arc plasma deposition on powder particles 
The Petri dish was set in motion after evacuation using the vibration system which was powered by a function generator. The frequency was tuned to the resonance frequency of the mechanical system $(20 \mathrm{~Hz})$. The motion of the dish including the powder could be observed through a window and easily controlled by choosing a suitable power amplitude (about $5 \mathrm{~V}$ into $8 \Omega$ impedance, i.e. about $0.6 \mathrm{~W}$ ) and frequency. The motion of powder particles depends very much on these parameters; they were chosen such as to make the particles "dance" up to a few millimeters above the bottom of the Petri dish. Experiments with 1.5 micron $\mathrm{Al}_{2} \mathrm{O}_{3}$ powder (alpha, 99.99\% purity of metal basis) showed that these very small powder particles tend to agglomerate, and therefore we restricted our experiments to powder of mesh size 60 .

After the motion of powder particles was initiated, the platinum plasma source was switched on. It operated in a pulsed mode with an arc current of $150 \mathrm{~A}$, arc duration $1 \mathrm{~ms}$, and arc repetition rate of 5 pulses per second (thus the arc duty cycle was $0.5 \%$ ). No macroparticle filter was used because platinum macroparticles can be tolerated in catalytic application. The deposition experiments were stopped after 4000 arc pulses (about $13 \mathrm{~min}$.).

\section{RESULTS AND DISCUSSION}

The powder particles were investigated using scanning electron microscopy and Auger electron spectroscopy. Both methods show clearly that all particles were completely covered with platinum. An example of an Auger electron spectroscopy survey is shown in Fig. 3; no oxygen or aluminum signals were detected, hence platinum coverage is complete. A platinum film thickness of about $100 \mathrm{~nm}$ was derived.

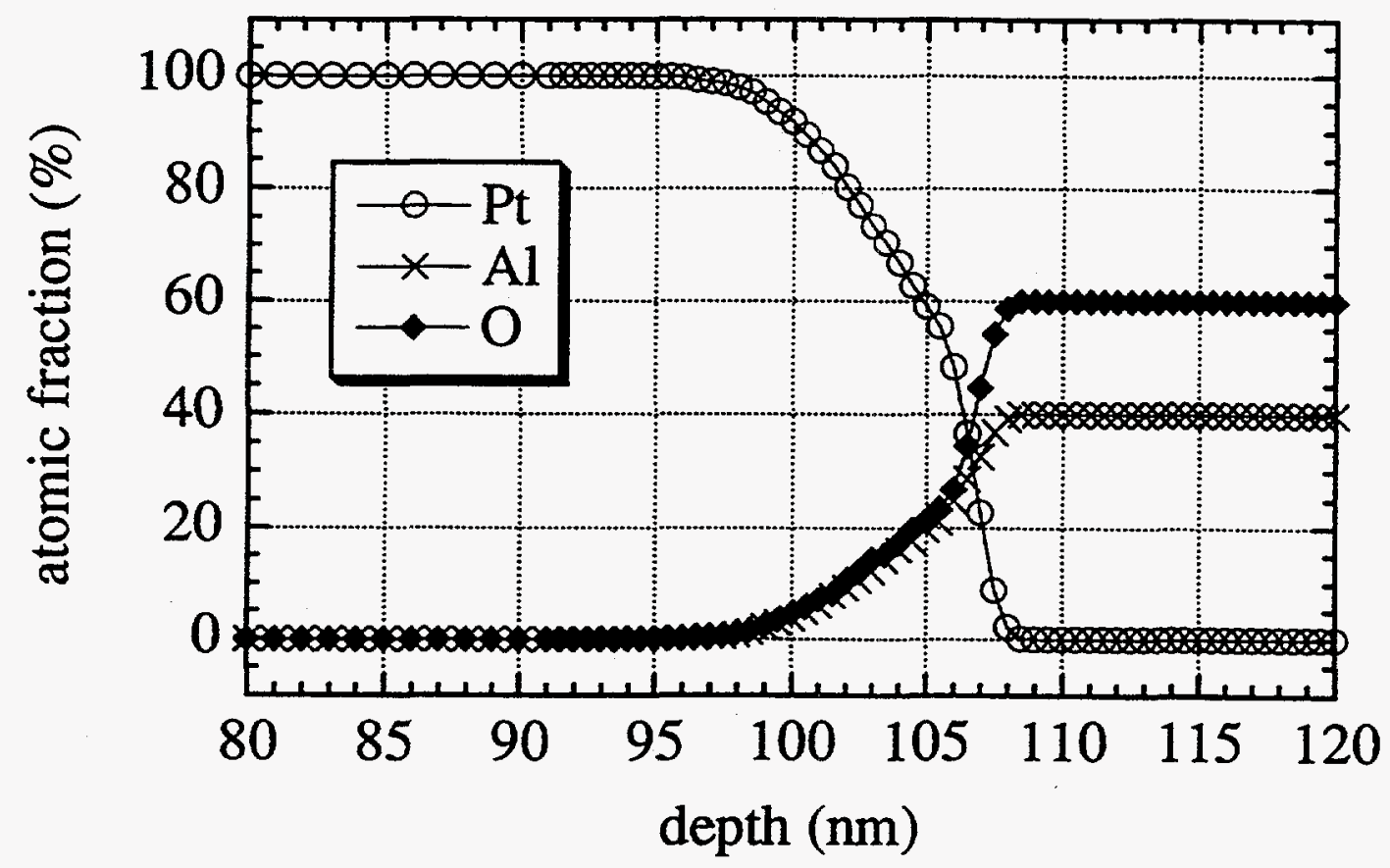

Fig. 3 Auger electron spectroscopy survey of alumina powder (mesh 60) coated with platinum. Note that only Pt signals are observed.

The typical kinetic ion energy of platinum ions in the cathodic arc plasma jet is about 300 $\mathrm{eV}$, and thus the impact onto a substrate surface causes intermixing. We could not find any indication that the platinum film peels off the powder particles, and so we assume that adhesion is very good. Previous experiments in the field of cathodic arc plasma deposition show that intermixing of substrate and film occurs, and it seems reasonable to attribute good adhesion to intermixing also under the present conditions. Fig. 4 shows deposition with intermixing calculated by the Monte Carlo code T-DYN [20]. 


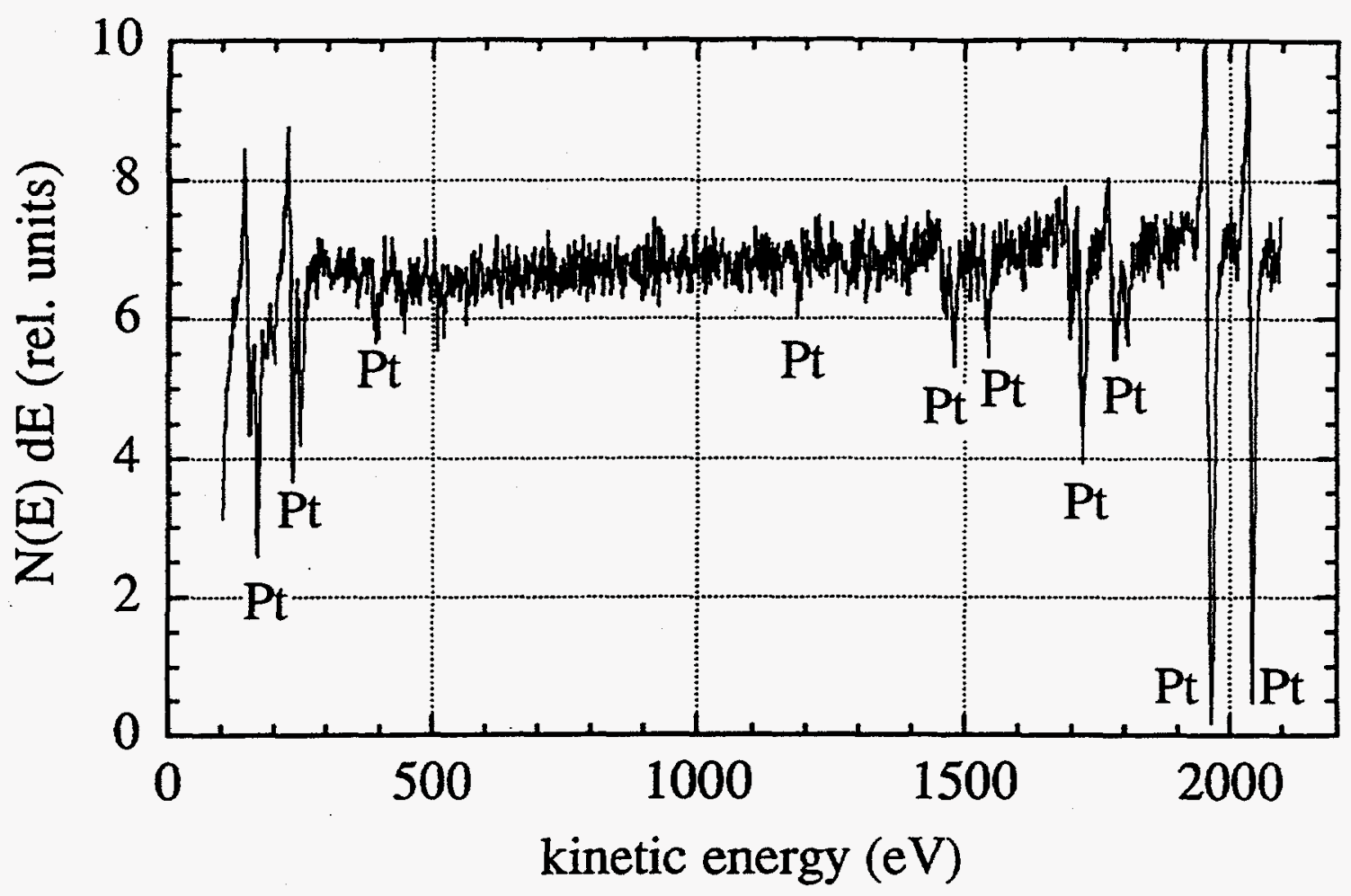

Fig. 4 Deposition of $300 \mathrm{eV}$ platinum ions on a $\mathrm{Al}_{2} \mathrm{O}_{3}$ substrate (T-DYN simulation).

The pulse operating mode allows working with a small average arc power (in the present experiment $15 \mathrm{~W}$ ), and thus it requires only small, relatively low-cost equipment and no cooling of plasma source and substrate. For industrial application, however, it seems inevitable to operate a dc arc facility. The actual deposition time was only 20 seconds in our experiment, and thus the actual deposition rate was $5 \mathrm{~nm} / \mathrm{s}$. For comparison, sputter coating of $\mathrm{YBa}_{2} \mathrm{Cu}_{3} \mathrm{O}_{7}$ powder (diameter $80 \mu \mathrm{m}$ and smaller) with silver took several hours with a rate smaller than $0.1 \mathrm{~nm} / \mathrm{s}$ [3]. Therefore, cathodic arc plasma deposition can be considered as a high-rate (and therefore lowcost) method providing superior film properties such as good adhesion. Another advantage is that deposition (including reactive deposition) can be done with the substrate at room temperature. For comparison, deposition of TiN on iron powder (mesh 150-200) was done at a temperature of about $1000^{\circ} \mathrm{C}$ with a deposition rate of $0.2 \mathrm{~nm} / \mathrm{s}$ [2]. Cathodic arc plasma deposition is an environmentally friendly method since no hazardous waste is generated. In contrast, reactive gases and solvents are used in chemical vapor deposition on powders $[1,2]$.

In conclusion, we have shown that cathodic arc plasma deposition is a high-rate, low-cost, environmentally friendly deposition method which can be extended to coatings of powders. As an example we have demonstrated film synthesis of platinum ( $100 \mathrm{~nm}$ thickness) on $\mathrm{Al}_{2} \mathrm{O}_{3}$ powder $($ mesh 60$)$ at a rate of $5 \mathrm{~nm} / \mathrm{s}$.

\section{ACKNOWLEDGMENT}

This work was supported by the Electric Power Research Institute under RP 8042-03 and the U.S. Department of Energy, Division of Advanced Energy Projects, under contract No. DEAC03-76SF00098. 


\section{REFERENCES}

[1] C. F. Powell, J. H. Oxley, and J. M. Blocher Jr., Vapour Deposition, (Wiley, New York, 1966).

[2] H. Itoh, K. Hattoria and S. Naka, J. Mater. Sci. 24, 3643 (1989).

[3] H. R. Khan and H. Frey, J. of the Less-Common Metals 175, 177 (1991).

[4] A. K. Garg and L. C. De Jonghe, J. Mater. Res. 5, 136 (1990).

[5] W.-J. Kim, Y. T. Moon, C. H. Kim, D. K. Kim, H.-W. Lee, J. Mater. Sci. Lett. 13, 1349 (1994).

[6] J. M. Lafferty (Editor), Vacuum Arcs, (Wiley Interscience, New York, 1980).

[7] B. Jüttner, IEEE Trans. Plasma Sci. 15, 474 (1987).

[8] G. A. Mesyats and D. I. Proskurovsky, Pulsed Electrical Discharge in Vacuum, (Springer, Berlin, 1989).

[9] A. Anders, S. Anders, B. Jüttner, W. Bötticher, H. Lück, and G. Schröder, IEEE Trans. Plasma Sci. 20, 466 (1992).

[10] P. J. Martin, R. P. Netterfield, and T. J. Kinder, Thin Solid Films 193, 77 (1990).

[11] A. Bendavid, P. J. Martin, R. P. Netterfield, and T. J. Kinder, Surface and Coatings Technology 70, 97 (1994).

[12] D. R. McKenzie, D. Muller, B. A. Pailthorpe, Z. H. Wang, E. Kravtchinskaya, D. Segal, P. B. Lukins, P. D. Swift, P. J. Martin, G. Amaratunga, P. H. Gaskell, and A. Saeed, Diamond and Related Materials 1, 51 (1991).

[13] R. Lossy, D. L. Pappas, R. A. Roy, J. J. Cuomo, and V. M. Sura, Appl. Phys. Lett. 61, 171 (1992).

[14] I. I. Aksenov, S. I. Vakula, V. G. Padalka, V. E. Strel'nitskii, and V. M. Khoroshikh, Zhurn. Tekh. Fiz. 50, 2000 (1980); Sov. Phys.-Tech. Phys. 25, 1164 (1980).

[15] A. Anders, S. Anders, and I. G. Brown, Plasma Sources Sci. \& Technol. 4, 1 (1995).

[16] R. L. Boxman and S. Goldsmith, Surface Coatings Technol. 52, 39 (1992).

[17] A. Anders, S. Anders, I. G. Brown, Mat. Res. Soc. Symp. Proc. 316, 833 (1994).

[18] I. G. Brown, A. Anders, S. Anders, R. A. Castro, M. R. Dickinson, R. A. MacGill, and Z. Wang, presented at the Ninth International Conference on Ion Beam Modification of Materials, Canberra, Australia, 1995 (unpublished).

[19] R. A. MacGill, S. Anders, A. Anders, R. A. Castro, M. R. Dickinson, K. M. Yu, and I. G. Brown, Surface Coatings Technol. (1995) accepted for publication.

[20] J. P. Biersack, S. Berg, and C. Nender, Nucl. Instrum. Meth. Phys. Res. B59/60, 21 (1991). 